\title{
PREFERENCES OF THE CENTRAL BANK OF BRAZIL UNDER THE INFLATION TARGETING REGIME: ESTIMATION USING A DSGE MODEL FOR A SMALL OPEN ECONOMY
}

\author{
Andreza Aparecida Palma ${ }^{\mathrm{a}}$ \\ Marcelo SavinoPortugal $^{\mathrm{b}}$
}

\begin{abstract}
Resumo: O objetivo principal deste trabalho é estimar as preferências do Banco Central do Brasil no período pós metas de inflação (janeiro 2000 a junho de 2011), usando um modelo DSGE com fundamentos microeconômicos para uma pequena economia aberta, tomando como base especialmente o trabalho de Kam, Lees e Liu (2009). O modelo utilizado neste trabalho considera que o Banco Central minimiza uma função perda, levando em consideração o desvio da inflação em relação a meta, a estabilização do produto, a suavização da taxa de juros e, distintamente dos trabalhos anteriores, a taxa de câmbio. Os resultados permitem afirmar que a maior preocupação da autoridade monetária no período foi com a estabilização da inflação, seguida pela suavização da taxa de juros, estabilização do produto e, por último, a estabilização da taxa de câmbio.
\end{abstract}

Palavras-chave: política monetária, preferências do Banco Central do Brasil, estimação bayesiana, DSGE.

JEL: C11, E12, E52, E61

\begin{abstract}
The main objective of this paper is to estimate the preferences of the Central Bank of Brazil after the inflation targeting regime (January 2000 to June 2011), using a DSGE model with microeconomic foundations for a small open economy, based especially on the work of Kam, Lees and Liu (2009). The model used in this study considers that the Central Bank minimizes a loss function, taking into account the deviation of inflation from its target, output stabilization, the interest rate smoothing and, unlike the previous works, the exchange rate. The results allow us to affirm that the major concern of the monetary authority in the period was the stabilization of inflation, followed by interest rate smoothing, output stabilization and, finally, exchange rate stabilization.
\end{abstract}

Keywords: Monetary policy, Central Bank preferences, Bayesian estimation, DSGE. JEL codes: C11, E12, E52, E6.

Submetido para área ANPEC 4 - Macroeconomia, Economia Monetária e Finanças

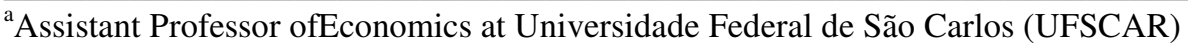

Email: drepalma@gmail.com

Phonenumber: 55-15-3031-4247

${ }^{\mathrm{b}}$ Professor of Economics at both Graduate Program in Business Administration (PPGA) and Graduate Program in Economics (PPGE) at Universidade Federal do Rio Grande do Sul (UFRGS).

Email: $\underline{\text { msp@ @ufrgs.br }}$
} 


\section{Introduction and Justification for the Study}

One of the major developments in macroeconomics in the past few decades has been theadoptionof the intertemporal utility maximization paradigmand its implementation in dynamic stochastic general equilibrium (DSGE) models, which are currently the predominant approach to macroeconomic analysis, not only among scholars, butincreasingly among Central Banksworldwide.

In DSGE models, economic agents (consumers andfirms) are treated as optimizing agents. Thus, families maximizeutilityconditional on some given budget constraint and firms maximizetheir profits with the applicable constraints. However, the Central Bank's behavior is often described asa special case, i.e., by a monetary policy rule- the Taylor rule. Unlike other agents, mostly through DSGE models, the Central Bankdoes not solveits optimization problem.

The Taylor rule,the standard tool for assessing the behavior of Central Banks, empirically describes the monetary authority's response to macroeconomic variables. Although it was proposed from a purely empirical perspective, the Taylor rule has a theoretical basis, being the solution to a restricted optimization problem, where the Central Bank minimizes a quadratic loss function. ${ }^{1}$ This way, the coefficients estimatedin a reaction function are rather complex combinationsof preference parameters (coefficients of the objective function) of the monetary authority and structural parameters of the model. Therefore, the coefficients found in the reaction function are reduced-form estimatesand do not describe the structural characteristics of the monetary policy, and are then not useful for assessing issuesconcerned with the process of monetary policyformulation.

The aim of the present paper is to symmetricallydeal with the monetary authority in a DSGE model, i.e., to assume that the Central Bank is also an optimizing agent and minimizes its loss function conditional on economic constraintsand, based on this problem, to estimate the monetary authority's preferences. Few works used a similar approach to the international case. Ilbas (2010b) and Ilbas (2010a) estimate FED's preferencesand the preferences for the euro zone, respectively, following the model proposed by Smets and Wouters (2003), under commitment. Kam, Lees and Liu (2009), on the other hand, estimate the central bank preferencesfor three of the major small open economies that operate under the inflation targeting regime: Australia, Canadaand New Zealand. The authors use a quadratic loss function and the model put forward by Monacelli (2005) as a constraint on the optimization problem, taking into account the discretionary case.In the Central Bank's loss function, the following variables are used as arguments: deviation of inflation, of output, interest rate smoothing, and exchange rate. Remo and Vasícek (2009) do the same for the Central Bank of the Czech Republic, but they use commitment instead. In the loss function, the authors do not regard the exchange rate as argument.

Getting to know the Central Bank's preferences is of utmost importance. Many inflation episodes, for instance, may arise from the monetary authority's attempt to stabilize outputabove its natural rate. Moreover, the heavier the relative weight of output on the loss function, the larger the inflationary bias towards the economy. According to Castelnuovo and Surico (2003, p. 336), knowing the monetary policy preferences allows assessingits performance in a more accurate fashion, since it is possible to know whether the obtained result is that which was actuallysought by the Central Bank or whether it represents just a random gain from favorable macroeconomic conditions.

In Brazil, Aragon and Portugal (2009) were the first authors to investigate the monetary authority's preferences. In a calibration exercise of the loss function, the authors, using a backward-looking model, choose preference parameter values that minimize the deviationbetween the simulated optimal path and the actual path of the Selic rate. Given that in a calibration exercise, inference would not be possible, the optimal structure is employed to estimate preferences through the maximum likelihood method.The results indicate that the Central Bank of Brazil places a

${ }^{1}$ Proposed by Svensson (1996). 
heavier weighton the inflation rateand that the concern with interest rate smoothing isdeeper than with the output gap. Nevertheless, it should be noted that in the maximum likelihood estimation exercise the loss function parameterswere not significant. This fact, as pointed out by the authors, might have occurred owing to the small sample size.

Palma and Portugal (2011) used a standard new-Keynesian modelwith forward-looking expectations proposed by Givens (2010) to estimate the monetary authority's preferences in Brazilduring the inflation targeting regime, taking into account a closed economy. ${ }^{2}$ Assuming rational expectations, it is necessary tomake a key distinction about how agents' expectations are dealt with in the optimization problem, i.e., by telling commitment and discretion apart. The main differencebetween these two possibilities lies in how agents' expectations aretreated in the Central Bank's optimization problem. Equilibrium in both cases takes the form of a state-space model that can be estimated by maximum likelihood using the Kalman filter. The results show that the monetary authority places a heavier weight on inflation stabilization, followed by interest rate smoothingand by output stabilization. In addition, the results obtained by the authors indicate that a discretionary policyis more consistentwith the data available for the analyzed period.

The present paper does innovate, offering a one-of-a-kind study for the Brazilian case, by using a DSGE model, which is more consistent with the optimization and rational expectations approach.

The utilization of forward-looking expectationshighlights the central role of expectations formation, especially under the inflation targeting regime, underscoring the importance of future events for the present time. Furthermore, the use of Bayesian methods in the estimation process is quite attractive due to theshort duration of the sample period.

The aim of the present paperis to use the Bayesian approach to estimate the monetary authority's preferencesbased on a DSGE model, where all structural equations result from optimal decisionsmade by private agents and policymakers in a discretionary context. ${ }^{3}$ The intention is to contribute to improving the insight into monetary policy conduct in Brazil under the inflation targeting regime,managing to remedy some shortcomings seen in previous works on the same topic. The Bayesian approach is quite attractive for this case, given that the sample for the inflation targeting regime is somewhat small.

The remainder of this paper is organized as follows. Section 2 introduces the methodology used, with a brief description of DSGE models and their estimation by Bayesian methods. Section 3 outlines the theoretical model used in the present paper, which is based chiefly on Kam, Lees and Liu (2009). Section 4 presents the data and the selection of priors, as well as the results. Section 5 concludes.

\section{Method}

\subsection{DSGE Models}

In the 1960s and 1970s, the large-scale macroeconomic models (systems of equations) arose as an attractive tool for policymakers and economists. However, these models were harshly criticizedon the grounds of their empirical, and mainly theoretical, foundations, since they were especiallysubject to Lucas (1976) critique, according to which, changes in economic policymodify agents' expectationsand, in turn,alter the parameters of economic models. The implications for the systems of equations models arecatastrophic, as these models are believed to beof little value.

As an alternative, Kydland and Prescott (1982) proposed the first model that used a DSGE approach, or thereal business cycle (RBC)approach tomacroeconomic modeling. Nonetheless, total price flexibility was considered at first, implying thatmonetary authority's actionsdo notinfluence

\footnotetext{
2 The authors tried to minimize this constraint by using a monetary conditions index (MCI) as monetary policy instrument, which is a weighted average between the interest rate and the exchange rate, in lieu of interest rates. However, the results did not vary significantly.

${ }^{3}$ A discretionary environment was chosen, a priori, considering the results obtained by Palma and Portugal (2011).
} 
real variables. Because of that, these models were initially unattractive for Central Banks and other organizations.

With the advent of nominal and real rigidities in the 1990s, besides imperfect competition in DSGE models, they eventually proved to be veryuseful in capturing important characteristics of macroeconomic time series, unlike their predecessor (the RBC models proposed by Kydland and Prescott). Aside from that, improvements in quantitative methods werekey toarousing the interest in these models. Since then, these models have been constantly improved and, currently, DSGEmodels are the standard tool for macroeconometricanalysis, and can be used for several purposes,such as estimation, prediction, comparison of models, identification of shocksand analysis of economic policies. The addition of expectations to these models renders them lessvulnerable to Lucas critique than conventional models, where expectations are not used orare used in a limited way.

DSGE models are open to many criticisms, though. One of their limitations is that they develop strong hypotheses about the agents' rationality. In addition, the heterogeneity of individuals is not taken into proper consideration.

In Brazil, improvements in DSGE models are particularly interesting given the adoption of the inflation targeting regime. Monetary policy is not randomly implemented and the Central Bankneeds a vast array of modelsand toolsto support its decisions, and DSGE models have taken onan increasingly important role.

\subsection{Estimation of DSGE models ${ }^{4}$}

The estimation of DSGE models poses several challenges, since their parameters are highly nonlinear. Initially, these models were solved by calibration, a technique that basically consists in setting parameter values based on some prior knowledge. For formal estimation, one of the first approaches was the generalized method of moments, which includes endogenous and expectational variables, found in the relationships defined by the model. However, this strategy was not so robust in that it may be necessary to use quite big samples to have useful inferences.

Notwithstanding the numerous criticisms, Bayesian methods have become quite popularand are particularly suitable for the estimation of the modelscontemplated herein. Simply put, Bayesian statistic can be considered a mix of calibration and the maximum likelihood principle. Uncertainty, as well as previous knowledge about the model and its parameters, is described by prior probabilities. Comparison with the data via the likelihood function leads to the revision of these probabilities, yielding the posterior probabilities.

A DSGE model is basically a nonlinear system of equations in expectational differences, which can be written in the following general matrix form:

$E_{t}\left[f_{\theta}\left(y_{t+1}, y_{t}, y_{t-1}, \varepsilon_{t}, \varepsilon_{t+1}\right)\right]=0$

where

$\varepsilon_{t} \sim$ i.i.d. $\left(0, \Omega_{\varepsilon}\right)$ is a random vectorof size $\mathrm{r} \times 1$ of structural shocks

$E_{t}\left(\varepsilon_{t+1}\right)=0$

$E_{t}\left(\varepsilon_{t+1} \varepsilon_{t+1}^{\prime}\right)=\Omega_{\varepsilon}$

$y_{t}=$ vector of endogenous variables

As observed above, the model is stochastic, forward-looking and nonlinear. Regardless of the estimation method, it is necessary to solve this model first andto obtain its reduced form. To do that, a linear approximation to the model is performed at first and, through methods for the

\footnotetext{
${ }^{4}$ This section is widely based on Adjemian (2007).
} 
solution of rational expectations models, a solution is found to the linear system, expressed in terms of deviations from the steady state. Some of the solution methods frequently usedare: Blanchard and Kahn, Sims, Klein, undetermined coefficients, among others. ${ }^{5}$

Assuming there is a unique stable and invariant solution, it is given by an equation in nonlinear stochastic differences, where the endogenous variables are written as a function of their previous levels and of the contemporaneous structural shocks:

$y_{t}=g_{\theta}\left(y_{t-1}, \varepsilon_{t}\right)$

$g_{\theta}$ is a set of policy functions.

In general, it is not possible to obtain a closed solution to the model, and (local or global) approximation methods then have to be used. The Dynare software uses a local approximationaround the deterministic steady state $(\bar{y}(\theta))$, i.e., the model is linearized around $\bar{y}(\theta)$, such that $f_{\theta}(\bar{y}, \bar{y}, \bar{y}, 0,0)=0$ and $y^{*}=g_{\theta}\left(y^{*}, 0\right)$.

Substituting (2.2) into (2.1) for $y_{\mathrm{t}}$ and $\mathrm{y}_{\mathrm{t}+1}$ :

$E_{t}\left[f_{\theta}\left(g_{\theta}\left(g\left(y_{t-1}, \varepsilon_{t}\right), \varepsilon_{t+1}\right), g_{\theta}\left(y_{t-1}, \varepsilon_{t}\right), y_{t-1}, \varepsilon_{t+1}, \varepsilon_{t}\right)\right]=0$

Each equation in (2.1) can then be approximated by the expected value of a Taylor expansion of its logarithm around the steady state (log-linearization). The equations in (2.1) and (2.2) can be approximated,using the following system (variables with acaretover them stand for percentage deviations of the original variablesfrom their steady state):

$E_{t}\left\{f_{y+1} \hat{y}_{t+1}+f_{y} \hat{y}_{t}+f_{y-1} \hat{y}_{t-1}+f_{\varepsilon+1} \varepsilon_{t+1}+f_{\varepsilon} \varepsilon_{t}\right\}=0$

$\hat{y}_{t}=g_{y-1} \hat{y}_{t-1}+g_{\varepsilon} \varepsilon_{t}$

where

$f_{y+1}=\frac{d f_{\theta}}{d y_{t+1}} f_{y}=\frac{d f_{\theta}}{d y_{t}} f_{y-1}=\frac{d f_{\theta}}{d y_{t-1}} f_{\varepsilon+1}=\frac{d f_{\theta}}{d \varepsilon_{t+1}} f_{\varepsilon}=\frac{d f_{\theta}}{d \varepsilon_{t}}$

$g_{y-1}=\frac{d g_{\theta}}{d y_{t-1}}\left(\right.$ feedback matrix $\left.{ }^{6}\right) \quad g_{\varepsilon}=\frac{d f_{\theta}}{d \varepsilon_{t}}\left(\right.$ feedforward matrix $\left.{ }^{7}\right)$

The model in its linearized form can be solved with the help of the Dynare software in order to obtain its representation in its reduced state-space form. As a matter of fact, a series of complex algebraic procedures is needed. ${ }^{8}$ After finding the solution to the model in terms of its policy functions, one can write it in state-space form:

$y_{t}^{*}=F \hat{y}_{t}+G u_{t} \quad$ measurement equation

$\hat{y}_{t}=D \hat{y}_{t-1}+G \varepsilon_{t} \quad$ state equation

Maximum likelihood estimation requires thatthe likelihood function be constructed and assessed based on the structural parameters. This is complicated when the model includes unobservable state variables. In this case, the Kalman filter, for instance, allows making inferences about the unobservable state vectorand assessing the joint likelihood function of observable endogenous variables, yielding consistent and asymptotically normal estimatesfor the parameters of interest.

\footnotetext{
${ }^{5}$ See details in Dejong and Dave (2007).

${ }^{6}$ It represents the impact of endogenous variables on forward-looking variables.

${ }^{7}$ It represents the impact of shocks on forward-looking variables.

${ }^{8}$ For a detailed description of these procedures, see Klein (2000) and Sims (2002).
} 
If the DSGE model isstochastically singular (more observable variables than random shocks), maximum likelihood estimation often fails. When that occurs, two strategies can be considered: i) using at most as many observable variables as the number of structural shocks; ii) adding error terms in the state-space observation equation.

Nevertheless, empirical experience has demonstrated that it is too difficult to estimate a model by the maximum likelihood method. Usually, the function is flat in certain directions, giving rise to important identification problems. The solution came from Bayesian methods, where the identification problem is not a limiting factor.

The Bayesian statistic basically consists intreatingthe parameters as random variables. In the case of structural models, the use of Bayesian methods is a lot more attractive, since there is an interpretation for the parameters that are being estimated,facilitating the selection of priors.

The specification of priors for the parametersbegins with the selection of the functional form that is more suitable for the distribution. For example, one can use the possible interval for the parameter values as reference. Thus, the inverse gamma distribution is used for parameters with only positive values, the beta distribution is reserved forparameterswith values between 0 and 1 and normal distribution is used for unrestricted parameter values. The use ofnon-informative priors (uniform distribution) is also possible.

With the likelihood function and the specification of priors, it is possible to estimate the posterior distributions, which represent the probabilities associated with different parameter valuesafter observation of the data. Basically, the posteriorsare updates of beliefs, represented by the priors, based on additional information provided by variables in the sample. The determination of posteriors basically consists of the application of the widely known Bayes' Theorem:

where:

$$
p\left(\theta \mid y^{*}\right)=\frac{p\left(\theta, y^{*}\right)}{p\left(y^{*}\right)}=\frac{p\left(y^{*} \mid \theta\right) p(\theta)}{p\left(y^{*}\right)}
$$

$p\left(y^{*} \mid \theta\right)=$ likelihood function

$p(\theta)=$ informative priors

$p\left(y^{*}\right)=$ marginal density function of the sample.

Given that $p\left(y^{*}\right)$ does not rely on the vector of parameters, it can be treated as a constantand the posteriorcan be written as

$$
p\left(\theta \mid y^{*}\right) \propto p\left(y^{*} \mid \theta\right) p(\theta)=K\left(\theta \mid y^{*}\right)
$$

where $K\left(\theta \mid y^{*}\right)$ is known as the posteriorkernel and is proportional to the posteriordeterminedby factorp $\left(y^{*}\right)$.

The determination of posteriors includes the calculation of quite nontrivial integrals and computationally intensive numerical methods are needed. TheMarkov Chain Monte Carlo (MCMC) methods allow for this calculation. The basic idea of this method is to construct a Markov chain with state spaces in parametric space $\theta$, which is easy to simulate and whose equilibrium distributionis given exactly by the posterior distribution. The Metropolis-Hastings algorithm is one of the possibilities in this case.This algorithm is used herein and is summarized in what follows.

After defining a transition kernel, $q(\theta, \beta)$, of the priordistribution, use it to produce candidates:

i) Begin with a value $\theta^{(0)}$ and stage index $\mathrm{j}=0$;

ii) Generate a point $\beta$ from the transition kernel

iii) Update $\theta^{(j)}$ into $\beta=\theta^{(j+1)}$ with probability given by $\mathrm{p}=\min \left\{1 \mid \frac{p(\beta) q\left(\theta^{(j)}, \beta\right)}{p\left(\theta^{(j)}\right) q\left(\beta, \theta^{(j)}\right)}\right\}$

iv) $\operatorname{Keep} \theta^{(j)}$ with probability $1-\mathrm{p}$

v) Repeat the procedure aboveuntil a stationary distribution is obtained. 
Note that the computational cost of the implementation of DSGE models is relatively low. Using the Dynare software, the relevant issue focuses on the interpretation of results rather than on their mechanics.

\section{Theoretical Model}

The model used herein is based on the framework developed byGali and Monacelli (2005), Monacelli (2005) and Justiniano and Preston (2010), which has been widely used for the analysis of fiscal and monetary policies by the central banks of small open economies(Australia, New Zealand, Canada, Czech Republic, Brazil, etc.). In the original model, monetary policy is described by an empirical Taylor rule. FollowingIlbas (2010a, 2010b), and mainlyKam, Lees and Liu (2009), this hypothesis will be abandoned and we will assume that the monetary authority optimizes a quadratic loss function in a discretionary fashion, in accordance with the results obtained by Palma and Portugal (2011). This implies that the monetary authority reoptimizes the loss functionin each period, taking the agents' expectations as given. ${ }^{9}$

The aggregate demand and supply curvesare derived from the agents' optimization problem (families and firms, respectively) with forward-looking expectations. The source of real rigidityis the consumption habit persistence and that of the nominal rigidity is the indexation to the previous inflation, as well as the hypothesis of monopolistic competitionwith sticky prices for domestic and importing firms. Moreover, one should consider the imperfectexchange rate passthrough. ${ }^{10}$ Finally, we add the Central Bank's optimization problem instead of the Taylor rules to describe the behavior of the monetary policy. The model is therefore made up of four agents: families, domestic firms, importing firms and the monetary authority.

\subsection{Families}

In the model, there exists a continuum of identical familiesthat live infinitely, indexed by $i \in(0,1)$. The overall population equals one. The utility function is given by:

$U\left(C_{t}, H_{t}, N_{t}\right)=\frac{\left(C_{t}-H_{t}\right)^{1-\sigma}}{1-\sigma}-\frac{N_{t}^{1+\varphi}}{1+\varphi}$

where $C_{t}$ is a goods consumption index, $H_{t}$ represents external habit formation, given byan autoregressive process of order 1 , with parameter $\mathrm{h}$, and $N_{t}$ are the working hours. The inverse elasticity of intertemporal substitution is given by parameter $\sigma>0$, and the inverse of the elasticity of labor supplyis given by $\varphi>0$.

The goods consumption index, $C_{t}$, is a combination of a continuum of domestic goods, $C_{H, t}(i)$ and of imported goods, $C_{F, t}(j)$, given by the CES function:

$C_{t}=\left[(1-\alpha)^{\frac{1}{n}} C_{H, t}^{\frac{\eta-1}{\eta}}+\alpha^{\frac{1}{\eta}} C_{F, t}^{\frac{\eta-1}{\eta}}\right]^{\frac{\eta-1}{\eta}}$,

where

$C_{H, t}=\left[\int_{0}^{1} C_{H, t}(i)^{\frac{\varepsilon-1}{\varepsilon}} d i\right]^{\frac{\varepsilon}{\varepsilon-1}}$ and

\footnotetext{
${ }^{9}$ Note that the inflation targeting regime is an instrument that increases transparency, communication and coherence of the monetary policy, not necessarily consisting of a conventional strict commitment system (Bernanke and Mishkin, 1997). In fact, this regime is compatiblewith the discretionary behavior of the monetary policy. According to Mendonça (2001), owing to the transparency of the inflation targeting regime, it is possible to use discretionary policies without loss of credibility of the monetary authority.

${ }^{10}$ For further reading on this topic, see, for instance, Goldfajn and Werlang (2000).In short, with the imperfect exchange rate pass-through, importers do not immediately adjust the domestic price of importsin response to exchange ratefluctuations.
} 
$C_{F, t}=\left[\int_{0}^{1} C_{F, t}(j)^{\frac{\varepsilon-1}{\varepsilon}} d j\right]^{\frac{\varepsilon}{\varepsilon-1}}$

The elasticity of substitution between domestic and imported goods is given byparameter $\eta>0$, and the elasticity of substitution across goods withineach category ${ }^{11}$ (domestic and imported goods) is given by $\varepsilon>0$.

Solving the optimization problem of the families (utility maximization given the budget constraint), we obtain the following optimal demand functions:

$$
\begin{aligned}
C_{H, t} & =(1-\alpha)\left(\frac{P_{H, t}}{P_{t}}\right)^{-\eta} C_{t} \\
C_{F, t} & =\alpha\left(\frac{P_{F, t}}{P_{t}}\right)^{-\eta} C_{t}
\end{aligned}
$$

where $P_{H, t}$ and $P_{F, t}$ are the aggregate price levels for the domestic economy and for the foreign economy, given respectively by:

$P_{H, t}=\left(\int_{0}^{1} P_{H, t}(i)^{1-\varepsilon} d i\right)^{\frac{1}{1-\varepsilon}}$
$P_{F, t}=\left(\int_{0}^{1} P_{F, t}(j)^{1-\varepsilon} d j\right)^{\frac{1}{1-\varepsilon}}$

The consumer price indexis obtained by substituting the demand functions in the consumption index, $C_{t}$ :

$P_{t}=\left[(1-\alpha) P_{H, t}^{1-\eta}+\alpha P_{F, t}^{1-\eta}\right]^{\frac{1}{1-\eta}}$

\subsection{Firms}

\subsubsection{Domestic goods firms}

Domestic goods operate with a linear production function given by $Y_{H, t}(i)=\epsilon_{a, t} N_{t}(i)$, where $\epsilon_{a, t}$ is an exogenous domestic technology shock, which follows an $\operatorname{AR}(1)$ process, $Y_{H, t}(i)$ is the production of the ithfirm, $N_{t}(i)$ is the amount of hired labor.

Firms are monopolistically competitive, which introduces nominal rigidity in the model. In each period, a fraction $\theta_{H} \in[0,1]$ of the firms does not reoptimize their prices. Instead, these firms change their prices by indexing them to the previous inflation. The optimizing firms, however, solve their optimization problem, which is given by:

$\max _{P_{H, t}(i)} \mathbb{E}_{t} \sum_{s=0}^{\infty} Q_{t, t+s} \theta_{H}^{S} Y_{H, t+s}(i)\left[P_{H, t}(i)\left(\frac{P_{H, t+s-1}}{P_{H, t-1}}\right)^{\delta_{H}}-P_{H, t+s} M C_{H, t+s} e^{\varepsilon_{H, t+s}}\right]$

Subject to the constrained demand of theith firm:

$Y_{H, t+s}(i)=\left[\frac{P_{H, t}(i)}{P_{H, t+s}}\left(\frac{P_{H, t+s-1}}{P_{H, t-1}}\right)^{\delta_{H}}\right]^{-\varepsilon}\left(C_{H, t+s}+C_{H, t+s}^{*}\right)$

Parameter $\varepsilon>1$ is the elasticity of substitution between produced goods and $M C_{H, t}$ is the real marginal cost at time $t$, given by:

\footnotetext{
${ }^{11}$ Note that within each category (domestic and imported goods), there aredifferent products.
} 


$$
M C_{H, t}=\frac{W_{t}}{\epsilon_{a, t} P_{H, t}}
$$

The structural shock to the marginal cost is given by $\epsilon_{H, t} \sim$ i. i.d. $\left(0, \sigma_{H}\right)$ and $\delta_{H} \in[0,1]$ is the level of inflation inertia.

The log-linearized first-order conditions of this problemgive rise to the Phillips curve for domestic inflation, given by:

$\pi_{H, t-} \delta_{H} \pi_{H, t-1}=\beta\left(\mathbb{E}_{t} \pi_{H, t+1}-\delta_{H} \pi_{H, t}\right)+\lambda_{H}\left(m c_{H, t}+\epsilon_{H, t}\right)$

where

$$
\begin{gathered}
\lambda_{H}=\frac{\left(1-\beta \theta_{H}\right)\left(1-\theta_{H}\right)}{\theta_{H}} \\
m c_{H, t}=\varphi y_{t}-(1+\varphi) \epsilon_{a, t}+\alpha s_{t}+\frac{\sigma}{1-h}\left(y_{t}^{*}-h y_{t-1}^{*}\right)+q_{t}+\epsilon_{c, t}
\end{gathered}
$$

\subsubsection{Importing firms}

The basic idea is the same as for domestic firms and thus this section will be quite short. The model considers the monopolistic competition between importers and price setting à la Calvo. Furthermore, a gap is assumed between the price of imported goods denominated in domestic currency and the domestic price of imported goods, which can be explained by the fact that importing firms purchase imported goods at globally competitive prices. However, in the domestic economy, these firms are monopolistically competitive, redistributing these goods. This gap is given in log-linear terms by:

$\psi_{F, t}=e_{t}+p_{t}^{*}-p_{F, t}$

The solution to the optimization problem of importing firms (as in the previous section) leads to the Phillips curve for imported goods inflation, given by:

$\pi_{F, t}=\beta\left(\mathbb{E}_{t} \pi_{F, t+1}-\delta_{F} \pi_{F, t}\right)+\delta_{F} \pi_{F, t-1}+\lambda_{F}\left(\psi_{F, t}+\epsilon_{F, t}\right)$

where

$\lambda_{F}=\frac{\left(1-\beta \theta_{F}\right)\left(1-\theta_{F}\right)}{\theta_{F}}$ e $\psi_{F, t}=m c_{F, t}$.

\subsection{Terms of trade, real exchange rate and equilibrium}

In equilibrium, domestic output is equal to the total domestic demand (domestic and foreign demand) for produced goods, which in log-linear terms yields:

$y_{t}=c_{H, t}+c_{H, t}^{*}$

Performing the necessary substitutions, we get:

$y_{t}=(2-\alpha) \alpha \eta s_{t}+(1-\alpha) c_{t}+\alpha \eta \psi_{F, t}+\alpha y_{t}^{*}$

It is also possible to derive a relationship between terms of trade $\left(s_{t}\right)$, the real exchange rate $\left(q_{t}\right)$ and the gap in the law of one price $\left(\psi_{F, t}\right)$, given by: ${ }^{12}$

\footnotetext{
${ }^{12}$ For further details on the derivation of this relationship, see Kam, Lees and Liu (2009).
} 
$q_{t}=\psi_{F, t}-(1-\alpha) s_{t}$

In what follows, we present the linearized version of the model, equation for equation. ${ }^{13}$

\subsection{The log-linearized model}

The equations for the log-linearized model(i.e., the log-linear approximation to the firstorder conditions and the constraints that describethe equilibrium of the economy) are presented below. Detailed information on how to obtain these equationscan be found in Kam, Lees and Liu (2009). Note that terms of trade shocks, technology shocks, and real interest rate parity shocksare, for simplicity, treated as exogenous stochastic processes.

\section{Consumption Euler equation}

$c_{t}-h c_{t-1}=E_{t}\left(c_{t+1}-h c_{t}\right)-\frac{1-h}{\sigma}\left(r_{t}-E_{t} \pi_{t+1}\right)$

Domestic goods inflation

$$
\begin{gathered}
\pi_{H, t}=\beta E_{t}\left(\pi_{H, t+1}-\delta_{H} \pi_{H, t}\right)+\delta_{H} \pi_{H, t-1}+\lambda_{H}\left[\varphi y_{t}-(1+\varphi) \epsilon_{a, t}+\alpha s_{t}+\frac{\sigma}{1-h}\left(c_{t}-h c_{t-1}\right)\right] \\
+\lambda_{H} \epsilon_{H, t}
\end{gathered}
$$

Imported goods inflation:

$\pi_{F, t}=\beta E_{t}\left(\pi_{F, t+1}-\delta_{F} \pi_{F, t}\right)+\delta_{F} \pi_{F, t-1}+\lambda_{F}\left[q_{t}-(1-\alpha) s_{t}\right]+\lambda_{F} \epsilon_{F, t}$

Real interest rate parity condition

$E_{t}\left(q_{t+1}-q_{t}\right)=\left(r_{t}-E_{t} \pi_{t+1}\right)-\left(r_{t}^{*}-E_{t} \pi_{t+1}^{*}\right)+\epsilon_{q, t}$

Terms of trade equation (identity)

$s_{t}-s_{t-1}=\pi_{F, t}-\pi_{H, t}+\epsilon_{s, t}$

Goods market equilibrium condition

$y_{t}=(1-\alpha) c_{t}+\alpha \eta q_{t}+\alpha \eta s_{t}+\alpha y_{t}^{*}$

General inflation:

$\pi_{t}=(1-\alpha) \pi_{H, t}+\alpha \pi_{F, t}$

The exogenous stochastic processes for the terms of trade shocks, technology shocks and real interest rate parity shocks are written as:

$\epsilon_{j, t}=\rho_{j} \epsilon_{j, t-1}+v_{j, t}$

with $\rho_{j} \in(0,1)$ and $v_{j} \sim i . i . d .\left(0, \sigma_{j}^{2}\right)$, for $\mathrm{j}=\mathrm{s}$, a, q.

$\left(\begin{array}{l}\pi_{t}^{*} \\ y_{t}^{*} \\ r_{t}^{*}\end{array}\right)=\left(\begin{array}{ccc}a_{1} & 0 & 0 \\ 0 & b_{2} & 0 \\ 0 & 0 & c_{3}\end{array}\right)\left(\begin{array}{l}\pi_{t-1}^{*} \\ y_{t-1}^{*} \\ r_{t-1}^{*}\end{array}\right)+\left(\begin{array}{ccc}\sigma_{\pi^{*}} & 0 & 0 \\ 0 & \sigma_{y^{*}} & 0 \\ 0 & 0 & \sigma_{r^{*}}\end{array}\right)\left(\begin{array}{l}v_{\pi^{*}, t} \\ v_{y^{*}, t} \\ v_{r^{*}, t}\end{array}\right)$

where $\left(\begin{array}{c}v_{\pi^{*}, t} \\ v_{y^{*}, t} \\ v_{r^{*}, t}\end{array}\right) \sim N\left(0, I_{3}\right)$.

${ }^{13}$ The description of parameters is given in tables 2 and 3 . 


\subsection{Monetary Authority: Central Bank Preferences}

Optimal monetary policy, which makes a distinctionbetween the model presented aboveand that proposed byGali and Monacelli (2005), will be outlinedin what follows. The intertemporal loss function of a period of the Central Bank is given by: ${ }^{14}$

$L\left(\tilde{\pi}_{t}, y_{t}, q_{t}, r_{t}-r_{t-1}\right)=\frac{1}{2}\left[\tilde{\pi}_{t}^{2}+\mu_{y} y_{t}^{2}+\mu_{q} q_{t}^{2}+\mu_{r}\left(r_{t}-r_{t-1}+\varepsilon_{t}^{r}\right)^{2}\right]$

As can be seen above, the weight allocated to the inflation target is normalizedat unityand, therefore, the weights of the other variables $\left(\mu_{y}, \mu_{q}, \mu_{r} \in[0, \infty)\right)$ will be regarded asrelative to that of the inflation target. As the inflation target is fixed in time, it will be normalized at zero, since all variables in the model are expressed as deviations from their mean. The last term of the loss function, $\Delta r_{t}=\left(r_{t}-r_{t-1}\right)$, is justifiable by the fact that the monetary authority also worries about the financial stability or for considering the inertial behavior of the policy instrument.In addition, we allow for a shock to this variable, given by $\varepsilon_{t}^{r} \sim N\left(0, \sigma_{r}^{2}\right)$, which allows capturing the imperfect ability of the Central Bankto control the nominal interest rate. The inclusion of the exchange rate in the Central Bank's loss functionallows us to answer whether this variable is taken into consideration in the monetary authority's optimization problem.

The monetary authority's goal is to minimize the loss function, subject to structural economic equations(3.15)-(3.23), underdiscretion. The solution to the problem is found using thealgorithm proposed by Dennis (2004). In sum, the concept of Markov perfect equilibrium is used, where the Central Banknowadays (i.e., its contemporaneous decisions) is considered a Stackelberg leader and the private agents and the future Central Bank's actions are regarded as Stackelberg followers.

\section{Estimation and Results}

\subsection{Data and selection ofprior distributions}

The model presented above will be estimated by Bayesian methods, as described in section 2. The data used are log-linearized quarterly series of the following variables, for the period after the inflation targeting regime(January 2000 - June 2011), totaling 46 observations:

- Imported goods inflationdenominated in domestic currency, $\pi_{F, t}$;

- $\quad$ Real domestic exchange rate: R $\$ / U S \$$ (Ptax sale value at the end of the period), $q_{t}$;

- $\quad$ Final household consumption, $c_{t}$;

- $\quad$ Terms of trade - FUNCEX (exportsand imports), $s_{t}$;

- Real domestic GDP - seasonally adjusted index, $y_{t}$;

- $\quad$ Domestic inflation: IPCA index, $\pi_{t}$;

- $\quad$ Nominal interest rate: annualized Selic rate, $r_{t}$;

- U.S. inflation, $\pi_{t}^{*}$;

- U.S. output, $y_{t}^{*}$;

- U.S. interest rate, $r_{t}^{*}$.

\footnotetext{
${ }^{14}$ This quadratic function combined with linear restrictions produces linear decision rules. Moreover, it may represent a second-order approximation to the utility function of the representative agent.
} 
The series will be expressed as deviations from the sample mean and are available atwww.ipeadata.gov.br,on the website of the Central Bank of Brazil atwww.bcb.gov.br and on the website of IBGE atwww.ibge.gov.br. The variables were seasonally adjustedand the trend was removed using the Hodrick-Prescott (HP) filter.

Table 4.1 shows the prior distributionof the parametersto be estimated. The selection of priors takes into account mainly the interval of variation of each parameter. Conventionally, we use the beta distributionfor parameters that areon the interval [0,1],the inverse gamma distribution for those on the interval $[0, \infty)$ and the gamma distribution for the remaining cases.

Table4.1. Prior Distribution of the Parameters

\begin{tabular}{|c|c|c|}
\hline Parameter & Definition & Prior Distribution \\
\hline$\beta$ & Intertemporal discount rate & $0.99 *$ \\
\hline$\alpha$ & $\begin{array}{l}\text { Level of economic openness (share of } \\
\text { importsin domestic consumption) }\end{array}$ & $0.45^{*}$ \\
\hline$h$ & Habit persistence parameter & Beta $(0.7,0.1)$ \\
\hline$\sigma$ & $\begin{array}{l}\text { Inverseof the elasticity of substitution } \\
\text { (coefficient of relative risk aversion) }\end{array}$ & $\operatorname{Gamma}(0.2,0.2)$ \\
\hline$\phi$ & Inverse of the elasticity of labor supply & $\operatorname{Gamma}(2,0.35)$ \\
\hline$\eta$ & $\begin{array}{l}\text { Elasticity of substitution } \\
\text { betweendomestic and imported goods }\end{array}$ & $\operatorname{Gamma}(0.6,0.25)$ \\
\hline$\delta_{H}$ & $\begin{array}{l}\text { Backward-lookingparameter of the price } \\
\text { of domestic goods }\end{array}$ & $\operatorname{Beta}(0.7,0.2)$ \\
\hline$\delta_{F}$ & $\begin{array}{l}\text { Backward-lookingparameter of the price } \\
\text { of imported goods }\end{array}$ & Beta $(0.7,0.2)$ \\
\hline$\theta_{H}$ & $\begin{array}{l}\text { Fraction of non-optimizing producersin } \\
\text { the domestic economy }\end{array}$ & Beta $(0.5,0.2)$ \\
\hline$\theta_{F}$ & Fraction of non-optimizing importers. & Beta $(0.5,0.2)$ \\
\hline$a_{1}$ & Parameter AR(1) of foreign inflation & Beta $(0.5,0.1)$ \\
\hline$b_{2}$ & Parameter AR(1) of external output & Beta $(0.5,0.1)$ \\
\hline$c_{3}$ & Parameter $\mathrm{AR}(1)$ of foreign interest rate & Beta $(0.5,0.1)$ \\
\hline$\rho_{a}$ & Technological inertia & Beta $(0.8,0.1)$ \\
\hline$\rho_{q}$ & Inertial effect of exchange rate shock & Beta $(0.8,0.1)$ \\
\hline$\rho_{s}$ & Inertial effect of terms of trade shock & Beta $(0.8,0.1)$ \\
\hline$\mu_{q}$ & Preference for exchange rate stabilization & Gamma $(0.5,0.09)$ \\
\hline$\mu_{y}$ & Preference for output stabilization & Gamma $(0.5,0.09)$ \\
\hline$\mu_{r}$ & Preference for interest ratesmoothing & Gamma $(0.5,0.09)$ \\
\hline$\sigma_{H}$ & $\begin{array}{l}\text { Standard deviationof the "cost-push" } \\
\text { shock to the domestic economy }\end{array}$ & $\begin{array}{l}\text { Inverse gamma }(0.15, \\
2)\end{array}$ \\
\hline$\sigma_{F}$ & $\begin{array}{l}\text { Standard deviation of the "cost-push" } \\
\text { shock to the foreign economy }\end{array}$ & $\begin{array}{l}\text { Inverse gamma }(0.15, \\
2)\end{array}$ \\
\hline$\sigma_{a}$ & $\begin{array}{l}\text { Standard deviation of the technology } \\
\text { shock }\end{array}$ & $\begin{array}{l}\text { Inverse gamma }(0.15, \\
2)\end{array}$ \\
\hline$\sigma_{q}$ & & $\begin{array}{l}\text { Inverse gamma }(0.15, \\
2)\end{array}$ \\
\hline$\sigma_{s}$ & Standard deviation of the terms of trade & Inverse gamma $(0.15$ \\
\hline$\sigma_{\pi^{*}}$ & $\begin{array}{l}\text { Standard deviation of the foreign } \\
\text { inflation rate }\end{array}$ & Inverse gamma $(0.1,2)$ \\
\hline$\sigma_{y^{*}}$ & Standard deviation of the external output & $\begin{array}{l}\text { Inverse gamma }(0.15, \\
2)\end{array}$ \\
\hline$\sigma_{r^{*}}$ & Standard deviation of the foreign interest & Inverse gamma $(0.15$, \\
\hline
\end{tabular}




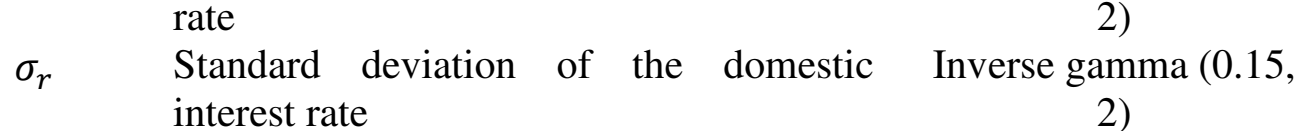

Note:The mean and standard deviation of the distributions are respectively shown in brackets.

* Denotes calibrated parameters.

\subsection{Results}

The model was estimated with Matlab, using Bayesian techniques through the MetropolisHastings algorithm andthe Kalman filter, ${ }^{15}$ as described in section 2. The results are shown in Table 4.1 .

Table 4.1.Model estimated under discretion

\begin{tabular}{|c|c|c|c|}
\hline Parameter & Posterior Mean & $95 \% \mathrm{CI}$ & $\begin{array}{l}\text { Standard } \\
\text { deviation }\end{array}$ \\
\hline \multicolumn{4}{|c|}{ Consumers } \\
\hline$h$ & 0.89 & {$[0.87 ; 0.90]$} & 0.01 \\
\hline$\sigma$ & 1.09 & {$[1.08 ; 1.10]$} & 0.01 \\
\hline$\phi$ & 1.71 & {$[1.62 ; 1.80]$} & 0.05 \\
\hline$\eta$ & 0.13 & {$[0.09 ; 0.18]$} & 0.03 \\
\hline \multicolumn{4}{|c|}{ Firms and Exogenous Processes } \\
\hline$\delta_{H}$ & 0.31 & {$[0.31 ; 0.32]$} & 0.00 \\
\hline$\delta_{F}$ & 0.07 & {$[0.06 ; 0.08]$} & 0.01 \\
\hline$\theta_{H}$ & 0.66 & {$[0.64 ; 0.69]$} & 0.02 \\
\hline$\theta_{F}$ & 0.87 & {$[0.82 ; 0.92]$} & 0.03 \\
\hline$a_{1}$ & 0.88 & {$[0.86 ; 0.89]$} & 0.01 \\
\hline$b_{2}$ & 0.83 & {$[0.78 ; 0.89]$} & 0.03 \\
\hline$c_{3}$ & 1.04 & {$[1.02 ; 1.07]$} & 0.02 \\
\hline$\rho_{a}$ & 0.77 & {$[0.76 ; 0.78]$} & 0.00 \\
\hline$\rho_{q}$ & 0.45 & {$[0.45 ; 0.48]$} & 0.01 \\
\hline$\rho_{S}$ & 0.85 & {$[0.83 ; 0.87]$} & 0.01 \\
\hline \multicolumn{4}{|c|}{ Monetary Policy } \\
\hline$\mu_{q}$ & 0.19 & {$[0.17 ; 0.21]$} & 0.01 \\
\hline$\mu_{y}$ & 0.51 & {$[0.50 ; 0.51]$} & 0.00 \\
\hline$\mu_{r}$ & 0.63 & {$[0.61 ; 0.64]$} & 0.01 \\
\hline \multicolumn{4}{|c|}{ Absolute weights: $\mu_{\pi}=0.4292, \quad \mu_{q}=0.0815, \mu_{y}=0.2189, \mu_{r}=0.2704$} \\
\hline \multicolumn{4}{|c|}{ Standard deviations of shocks } \\
\hline$\sigma_{H}$ & 0.84 & {$[0.81 ; 0.87]$} & 0.02 \\
\hline$\sigma_{F}$ & 3.67 & {$[3.60 ; 3.71]$} & 0.04 \\
\hline$\sigma_{a}$ & 7.78 & {$[7.72 ; 7.82]$} & 0.03 \\
\hline$\sigma_{q}$ & 2.64 & {$[2.51 ; 2.79]$} & 0.10 \\
\hline$\sigma_{s}$ & 4.91 & {$[4.85 ; 4.97]$} & 0.04 \\
\hline$\sigma_{\pi^{*}}$ & 0.80 & {$[0.73 ; 0.87]$} & 0.05 \\
\hline$\sigma_{y^{*}}$ & 0.64 & {$[0.56 ; 0.71]$} & 0.04 \\
\hline$\sigma_{r^{*}}$ & 0.51 & {$[0.47 ; 0.54]$} & 0.02 \\
\hline$\sigma_{r}$ & 3.84 & {$[3.64 ; 3.98]$} & 0.12 \\
\hline
\end{tabular}

${ }^{15}$ We used the codes kindly granted by Timothy Kam as reference. 
For the sake of comparison of the results obtained for the preference parameters, we show the results of previous studies for Brazil and for other countries that adopt the inflation targeting regime, in tables 4.2 and 4.3 , respectively.

Table 4.2. Comparison with previous studies

\begin{tabular}{|c|c|c|c|}
\hline $\begin{array}{l}\text { Preference } \\
\text { parameters }\end{array}$ & $\begin{array}{l}\text { Aragon and Portugal (2009) } \\
\text { - Calibration + Maximum } \\
\text { Likelihood } \\
\text { (backward-looking model) }\end{array}$ & $\begin{array}{l}\text { Palma and Portugal } \\
\text { (2011) -Kalman filter + } \\
\text { Maximum Likelihood } \\
\text { (Discretion) }\end{array}$ & $\begin{array}{l}\text { DSGE - Bayesian } \\
\text { methods (Discretion) }\end{array}$ \\
\hline \multicolumn{4}{|c|}{ 2000-1 to 2010-4 } \\
\hline$\mu_{\pi}$ & 2000 to 2007 & 0.8264 & 0.4292 \\
\hline$\mu_{y}$ & 0.727 & 0.0083 & 0.2189 \\
\hline$\mu_{r}$ & 0.073 & 0.1653 & 0.2704 \\
\hline$\mu_{q}$ & 0.2 & ------ & 0.0815 \\
\hline
\end{tabular}

Table 4.3. Comparison with the internationalliterature: "Small Inflation Targeters"

\begin{tabular}{|c|c|c|c|}
\hline $\begin{array}{l}\text { Preference } \\
\text { parameters }\end{array}$ & \multicolumn{1}{l|}{ Canada } & Australia & New Zealand \\
\hline \multicolumn{4}{|c|}{$\mathbf{1 9 9 0 - 1}$ to 2005-3 } \\
\hline$\mu_{\pi}$ & 0.4953 & 0.4931 & 0.4697 \\
\hline$\mu_{y}$ & 0.0778 & 0.2032 & 0.1282 \\
\hline$\mu_{r}$ & 0.4235 & 0.3013 & 0.3992 \\
\hline$\mu_{q}$ & 0.0035 & 0.0025 & 0.0028 \\
\hline
\end{tabular}

Source:Built based on the results obtained by Kam, Lees and Liu (2009)

As shown by the results above, the Central Bankattaches greater valueto the stabilization of inflation around its target(reference value, with weight equal to 1), followed by interest rate smoothing(0.63), by output stabilization(0.51)and, finally, by exchange rate stabilization $(0.19)$. The absolute weights are shown in table 4.1. Table 4.2 makes a comparison with previous results found in the literature. The order of parameter values does not change from one study to the other, but the magnitude is quite different.This is not a surprising result because we use a DSGE model, unlike other studies, which were conventional econometric models. In addition, the model used in this paper takes into account a small open economy, contrary to the previous studies. Palma andPortugal (2011) used a closed economy model and Aragon and Portugal (2009) employed only a random walk to describe the exchange rate behavior.

The results obtained herein show that the monetary authority attaches great weightto inflation stabilization, but a lower weight than those observed earlier. Moreover, note that there is a very deep concern with interest rate smoothing, with similar results to those published in the international literature. Kam, Lees and Liu (2009)found similar results for other "small open economies" that adopt the inflation targeting regime: Australia, Canadaand New Zealand. Also noteworthyis the fact that the weight given to output stabilizationis significantly heavier than thatattached in previous studies. This can be accounted for by the larger sample size used. In recent times, the Central Bank has apparentlygiven a larger weight to output gap, which may be helping to increase the weight of this variable in the loss function.

Conversely, the positive weight for the exchange rate smoothing parametercan be seen as an attempt toreduce the volatility of inflation in the short run, i.e., the weight of exchange in the reaction functionis indirectly associated with inflation control.

The habit formation parameter, estimated at 0.89 , shows the relevance of habit formationto Brazil. Silveira (2008) reports values for the first-order habit persistence between 0.55 and 0.81 . Silva and Portugal (2010) obtain a value of 0.9562, and a value of 0.74 for the SAMBA model for Brazil. According to Cavalcanti and Vereda (2011, p. 16), there are few references about 
persistence values for Brazil, since most recent works do not take this characteristic into consideration.Nonetheless, the value found herein is consistent with the recent literature.

The intertemporal elasticity of substitution in consumption (estimated at $0.92, \sigma=1.09$ ) is relatively higher than the values reported in the literature. Silveira (2008) found a value of 0.48 , and concluded that the aggregate demand responds to changes in the real interest rate, representing the conventional and effective monetary policy transmission mechanism in the Brazilian economy. Silva and Portugal (2010) also find lower values for the elasticity of substitution(1.2234, which implies an elasticity of 0.8174$)$. On the other hand, the SAMBA model estimates this parameter at0.77 $(\sigma=1.30)$. The result indicates thatthe tendency towards smoothing consumption in Brazil is quite strongand larger than in the euro zone (Silva and Portugal, 2010). As stated by Silveira (2008, p. 350), due to the large variability of the results, it is not possible to draw a definitive conclusion for this parameter. Specifically in our case, the posterior distribution is not very different from the prior one, probably indicatingpoor identification of this parameter. ${ }^{16}$

The elasticity of labor supplywas estimatedat $0.58(\phi=1.71)$. Silveira (2008) found a relatively larger value, 0.77 ( $\phi=1.30)$, as well as Gouvea et al. (2011), whoobtained 0.338 for this parameter (which implies an elasticity of 2.96). Yet, as suggested by the international literature, this value should be lower, as the one found herein. Silva and Portugal (2010)obtained a value of $\phi$ $=1.8128$ (elasticity of 0.55 ), quite close to the one estimated in this paper. This parameter can be interpreted asthe percentage change in labor supply given by a percentage change in real wage. The low value obtained here compared to other studies could refer to the specificity of rigidity in the Brazilian labor market.

The elasticity of substitution between domestic and imported goods was estimated at 0.13 , which indicates poor chances of substitution among these goods. The estimates for price stickiness parameters (Calvo) are consistent with the referenced literature. For the Brazilian economy, this elasticity was estimated at 0.66 and for the U.S. economy, at 0.87 . The estimates for the backwardlooking components of the Phillips curve were extremely low. The persistence parameters of exogenous processes are very high and most of themmatch those estimates described in the literature.

\section{Conclusion}

The major aim of this paper was to estimate the Central Bank preferences using a DSGE model for a small open economy, based chiefly on the work of Kam, Lees and Liu (2009). This topic has been investigated only recently for the Brazilian caseand, to the best of our knowledge, only two studies estimated the preferences of the Central Bank of Brazil: Aragon and Portugal (2009) and Palma and Portugal (2011). The present study innovatesin relation to both by considering a DSGE model and extending the work of Palma and Portugal (2011), for a small open economy. Additionally, the use of the exchange rate variable in the Central Bank's loss function isa noveltyfor the Brazilian case.

The model was estimated using quarterly data (in order to minimize measurement errors and the number of lags in the model) in the period that followed the inflation targeting regime(January 2000 to June 2011).Most of the results obtained for the structural economic parameters are consistent with the main previous studies that use DSGE models to assess issues related to the Brazilian economy.

As to the preference parameters, it is possible to assert that the Central Bank attaches heavier weight to the stabilization of inflation around its target, but that it is also interested in interest rate smoothing, output stabilization and exchange rate stabilization, in this strict order.

The study sought to improve the estimation of Central Bank preferences. To achieve that, a DSGE model with microeconomic foundations for a small open economy was used, consistent with the optimization and rational expectations approaches.Unlike most DSGE models, and an innovation

\footnotetext{
${ }^{16}$ As pointed out by Castro et al. (2011), the identification of this parameter is often cumbersome.
} 
for the Brazilian case, the monetary authority was regarded also as an optimizing agent. Contrary to other agents (families and firms, for example), in most of the studies using DSGE models, the Central Bank does not solve its optimization problem, and its behavior is described through the Taylor rule.

Some extensions to this study can and should be conducted in the future in order to improve and shed further light upon this important topic. One of them consists in including some elements of the SAMBA model, notably an equation for the inflation targetthat best describes the behavior of the Brazilian economy. In addition, as Palma and Portugal (2011) did, a version of the commitment model could be estimatedso as to check which of the two cases (commitments $x$ discretion) best suits the Brazilian case.

\section{REFERENCES}

Adjemian, S. (2007) Bayesian estimation of DSGE models. Available at: http://www.dynare.org/stepan/dynare/slides/BayesianEstimation.pdf.

Aragon, E. K.; Portugal, M. S. (2009) Central Bank Preferences and Monetary Rules under the Inflation Targeting Regime in Brazil.Brazilian Review of Econometrics, 29( 1).

Bernanke, B; Mishkin, F. (1997) Inflation targeting: a new framework for monetary policy?Journal of Economic Perspectives, 11(2).

Calvo, G.A. (1983) Staggered prices in a utility-maximizing framework. Journal of Monetary Economics. 12, 383-398.

Canova, F. (2007)Methods for applied macroeconomic research. Princeton, New Jersey: Princeton University Press.

Castelnuevo, E.; Surico,P. (2003)What does monetary policy reveal about a Central Bank's Preferences? Economic Notes, 32 (3), 335-359.

Castro, M.R.; Gouvea, S.N.; Minella, A.; Santos, R.C.; Souza-Sobrinho, N.F. (2011) SAMBA: Stochastic Analytical Model with a Bayesian Approach. Encontro Brasileiro de Econometria.

Cavalcanti, M.A.F.H.; Vereda, L. (2011) Propriedades dinâmicas de um modelo DSGE com parametrizações alternativas para o Brasil. IPEA. Texto para Discussão 1588, março 2011.

De Jong, D.N.; Dave,C.(2007) StructuralMacroeconometrics. Princeton, New Jersey: Princeton University Press.

Dennis, R. (2004) Inferring policy objectives from economic outcomes.Oxford Bulletin of Economics and Statistics, 66 (S1), 735-764.

Dennis, R. (2005) Inflation targeting under commitment and discretion. Economic Review, Federal Reserve Bank of San Francisco, 1-13.

Dennis, R. (2006) The policy preferences of the US Federal Reserve. Journal of Applied Econometrics, 21 (1),55- 77.

Gali, J.; Monacelli, T. (2005) Monetary policy and Exchange rate volatility in a small open economy. Review of Economic Studies, 72, 707-734.

Givens, G. (2010). Estimating Central Bank Preferences under Commitment and Discretion.Journal of Money, Credit, and Banking, forthcoming.

Goldfajn, I.; Werlang, S. R.C. (2000) The pass-through from depreciation to inflation: a panel study. Banco Central do Brasil Working Paper Series n. 5, Brasília, 2000.

Ilbas, P. (2010a) Estimation of monetary policy preferences in a forward-looking model: a Bayesian approach. International Journal of Central Banking, 6 (3), 169-209. 
Ilbas, P. (2010b)Revealing the preferences of the US Federal Reserve. Journal of Applied Econometrics, forthcoming.

Justiniano, A.; Preston, B. (2010) Monetary policy and uncertainty in an empirical small open economy model. Journal of Applied Econometrics, 25(1), 93-128.

Kam, T; Lees, K.; Liu, P. (2009) Uncovering the hit-list for small inflation targeters: a Bayesian structural analysis.Journal of Money, Credit and Banking, 41 (4), 583-618.

Klein, P. (2000)Using the generalized Schur form to solve a multivariate linear rationalexpectations model.Journal of Economic Dynamics and Control, 24 (10), 1405-1423.

Kydland, F.; Prescott, E. (1982) Time to build and aggregate fluctuations.Econometrica, 50, 1345-70.

Lucas, R.E. (1976) Econometric Policy Evaluation: a critique. In: Carnegie-Rochester Conference Series. The Phillips Curve.Amsterdam: North-Holland, p.19-46.

Mendonça, H. (2001) Mecanismos de transmissão monetária e a determinação da taxa de juros: uma aplicação da regra de Taylor ao caso brasileiro. Economia e Sociedade, 16, 65-81.

Monacelli, T. (2005) Monetary Policy in a Low Pass-through Environment, Journal ofMoney, Credit and Banking, 37, 1047-1066.

Palma, A.A.; Portugal, M.S. (2011) Preferences of the Central Bank of Brazil under the inflation targeting regime: commitment vs. discretion. RevistaBrasileira de Economia, 65, 347-358.

Remo, A.; Vasícek, O. (2009) Estimate of the Czech National Bank's Preferences in NOEM DSGE Model.BulletinoftheCzechEconometricSociety, 16 (26).

Silva, F. S.; Portugal, M. (2010) O impacto de choques fiscais na economia brasileira: uma abordagem DSGE. XXXII Encontro Brasileiro de Econometria (SBE), Salvador-BA.

Silveira, M. A. C. (2008) Using a Bayesian approach to estimate and compare new Keynesian DSGE models for the Brazilian economy: the role for endogenous persistence.Revista Brasileira de Economia, 62 (3), 333-357.

Sims, C. A. (2002) Solving linear rational expectations models.Computational Economics,20, (12), 1-20.

Smets, F.; Wouters , R. (2003) An estimated dynamic stochastic general equilibrium model of the Euro Area. Journal of European Economic Association, 1 (5), 1123-1175.

Svensson, L.E.O. (1996) Inflation forecast targeting: implementing and monitoring inflation targets. Cambridge: National Bureau of Economic Research. Working Paper, 5797. 